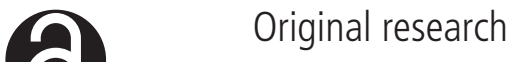

\section{Colorectal cancer risk following polypectomy in a multicentre, retrospective, cohort study: an evaluation of the 2020 UK post-polypectomy surveillance guidelines}

\author{
Amanda J Cross (1) , ${ }^{1}$ Emma C Robbins, ${ }^{1}$ Kevin Pack, ${ }^{1}$ Iain Stenson, ${ }^{1}$ Bhavita Patel, ${ }^{1}$ \\ Matthew D Rutter $10,{ }^{2,3}$ Andrew M Veitch, ${ }^{4}$ Brian P Saunders, ${ }^{5}$ Stephen W Duffy, ${ }^{6}$ \\ Kate Wooldrage ${ }^{1}$
}

\begin{abstract}
- Additional material is published online only. To view, please visit the journal online (http://dx.doi.org/10.1136/ gutjnl-2020-323411).

${ }^{1}$ Cancer Screening and Prevention Research Group (CSPRG), Department of Surgery and Cancer, Imperial College London, London, UK ${ }^{2}$ Department of

Gastroenterology, University Hospital of North Tees,

Stockton-on-Tees, UK

${ }^{3}$ Faculty of Medical Sciences, Newcastle University, Newcastle-upon-Tyne, UK ${ }^{4}$ Department of Gastroenterology, New Cross Hospital, Wolverhampton, UK ${ }^{5}$ Wolfson Unit for Endoscopy, St Mark's Hospital, Harrow, UK ${ }^{6}$ Centre for Cancer Prevention, Wolfson Institute of Preventive Medicine, Queen Mary University of London, London, UK
\end{abstract}

\section{Correspondence to} Professor Amanda J Cross, Cancer Screening and Prevention Research Group (CSPRG), Department of Surgery and Cancer, Imperial College London, London W2 1PG, UK; amanda.cross1@imperial.ac.uk

Received 19 October 2020 Revised 14 December 2020 Accepted 1 January 2021

Check for updates

(C) Author(s) (or their employer(s)) 2021. Re-use permitted under CC BY. Published by BMJ.

To cite: Cross AJ,

Robbins EC, Pack K, et al. Gut Epub ahead of print: [please include Day Month Year]. doi:10.1136/

gutjnl-2020-323411

\section{ABSTRACT}

Objective Colonoscopy surveillance aims to reduce colorectal cancer (CRC) incidence after polypectomy. The 2020 UK guidelines recommend surveillance at 3 years for 'high-risk' patients with $\geq 2$ premalignant polyps (PMPs), of which $\geq 1$ is 'advanced' (serrated polyp (or adenoma) $\geq 10 \mathrm{~mm}$ or with (high-grade) dysplasia); $\geq 5$ PMPs; or $\geq 1$ non-pedunculated polyp $\geq 20 \mathrm{~mm}$; 'low-risk' patients without these findings are instead encouraged to participate in population-based CRC screening. We examined the appropriateness of these risk classification criteria and recommendations.

Design Retrospective analysis of patients who underwent colonoscopy and polypectomy mostly between 2000 and 2010 at 17 UK hospitals, followed-up through 2017. We examined CRC incidence by baseline characteristics, risk group and number of surveillance visits using Cox regression, and compared incidence with that in the general population using standardised incidence ratios (SIRs).

Results Among 21318 patients, 368 CRCs occurred during follow-up (median: 10.1 years). Baseline CRC risk factors included age $\geq 55$ years, $\geq 2$ PMPs, adenomas with tubulovillous/villous/unknown histology or high-grade dysplasia, proximal polyps and a baseline visit spanning 2-90 days. Compared with the general population, CRC incidence without surveillance was higher among those with adenomas with high-grade dysplasia (SIR $1.74,95 \%$ Cl 1.21 to 2.42) or $\geq 2$ PMPs, of which $\geq 1$ was advanced $(1.39,1.09$ to 1.75$)$. For lowrisk (71\%) and high-risk (29\%) patients, SIRs without surveillance were 0.75 (95\% Cl 0.63 to 0.88$)$ and 1.30 (1.03 to 1.62), respectively; for high-risk patients after first surveillance, the SIR was 1.22 (0.91 to 1.60).

Conclusion These guidelines accurately classify postpolypectomy patients into those at high risk, for whom one surveillance colonoscopy appears appropriate, and those at low risk who can be managed by non-invasive screening.

\section{INTRODUCTION}

Colorectal cancer (CRC) can be prevented by removing premalignant polyps (PMPs), which include adenomatous and serrated polyps. ${ }^{1}$

\section{Significance of this study}

What is already known on this subject?

- Post-polypectomy surveillance aims to prevent colorectal cancer (CRC), or detect it early, following the removal of premalignant polyps (PMPs).

- The UK, EU and US surveillance guidelines were updated in 2020 to incorporate new data on long-term CRC incidence and mortality.

- The new UK guidelines recommend that 'high-risk' patients with $\geq 2$ PMPs, of which $\geq 1$ is 'advanced' (adenoma $\geq 10 \mathrm{~mm}$ or with high-grade dysplasia; serrated polyp $\geq 10 \mathrm{~mm}$ or with dysplasia); $\geq 5$ PMPs; or a single large $(\geq 20 \mathrm{~mm}$ ) non-pedunculated polyp undergo surveillance colonoscopy at 3 years. 'Low-risk' patients without these findings are encouraged to participate in their national CRC screening programme when invited rather than undergo surveillance.

- The accuracy of the classification criteria and the appropriateness of the surveillance recommendations in the new UK guidelines have not been investigated.

However, as polyps can recur, some patients are recommended surveillance colonoscopy to prevent future CRC. National guidelines tailor surveillance strategies according to baseline polyp characteristics. $^{2-7}$ Guidelines have largely been based on studies using surrogate endpoints for CRC, a method prone to overestimating risk, due to a lack of data on long-term post-polypectomy CRC outcomes. However, in 2020, the UK, EU and US post-polypectomy surveillance guidelines were revised to incorporate new data on long-term CRC incidence and mortality. ${ }^{6-8}$

The 2020 UK guidelines recommend surveillance at 3 years for patients with $\geq 2$ PMPs, of which $\geq 1$ is 'advanced' (adenoma $\geq 10 \mathrm{~mm}$ or with highgrade dysplasia; serrated polyp $\geq 10 \mathrm{~mm}$ or with dysplasia); $\geq 5$ PMPs; or $\geq 1$ large $(\geq 20 \mathrm{~mm})$ nonpedunculated PMP (LNPPMP). ${ }^{6}$ Patients without 


\section{Significance of this study}

What are the new findings?

- In our cohort of $\sim 21000$ patients with polyps, only those who had an adenoma with high-grade dysplasia or $\geq 2$ PMPs, of which $\geq 1$ was advanced, remained at increased risk of CRC after polypectomy.

- Applying the risk classification criteria in the new UK guidelines, $71 \%$ and $29 \%$ of our cohort were classified as low risk and high risk, respectively.

- Compared with the general population, CRC incidence was $25 \%$ lower among low-risk patients and 30\% higher among high-risk patients in the absence of surveillance.

- The excess risk in high-risk patients was reduced after one surveillance visit.

\section{How might it impact on clinical practice in the foreseeable future?}

- Healthcare professionals can be reassured that the new UK guidelines accurately identify patients at increased risk after polypectomy, and that a one-off surveillance colonoscopy is appropriate for these patients.

- The new UK guidelines will also help ensure that lowrisk patients are not exposed to unnecessary surveillance procedures and are appropriately managed by populationbased non-invasive CRC screening instead.

these findings are deemed at low risk and are encouraged to participate in their national CRC screening programme when invited rather than undergo surveillance. The $2020 \mathrm{EU}$ and US guidelines use similar polyp characteristics to identify patients requiring surveillance (eg, PMPs $\geq 10 \mathrm{~mm}$, high-grade dysplasia, $\geq 5$ PMPs). ${ }^{7}$

Several studies informed these guideline revisions ${ }^{9-17}$; however, only one of these compared post-polypectomy CRC incidence without surveillance to that in the general population, which is essential in determining surveillance requirements. This was our previous study of 11944 patients classified at baseline colonoscopy as 'intermediate risk' according to the 2002 UK surveillance guidelines. ${ }^{2910}$ Our analyses identified baseline CRC risk factors (incomplete colonoscopies, poor bowel preparation, adenomas $\geq 20 \mathrm{~mm}$, adenomas with high-grade dysplasia, proximal polyps) which discriminated patients remaining at increased risk after polypectomy and in need of surveillance from those not. ${ }^{9}{ }^{10}$

The authors of the new UK guidelines highlighted the need for further studies assessing long-term post-polypectomy CRC outcomes. The present study examined post-polypectomy CRC incidence by baseline patient, procedural and polyp characteristics among $\sim 21300$ patients over a median of 10.1 years and assessed the appropriateness of the risk classification criteria and surveillance recommendations in the new UK guidelines. ${ }^{6}$

\section{METHODS}

\section{Study design and participants}

This retrospective cohort study used data from patients who underwent colonoscopy with polypectomy at 17 UK hospitals from 1984 to 2010 (mostly (87\%) from 2000 to 2010). We previously used this cohort for our study of patients classified as 'intermediate risk' according to the 2002 UK guidelines, ${ }^{29} 10$ and a study examining all risk groups in these former guidelines ('low risk', 'intermediate risk', 'high risk'). ${ }^{18}$ For the present study, we obtained additional follow-up data on cancers and deaths. We examined the whole cohort combined and performed a stratified analysis applying the risk classification criteria in the 2020 UK guidelines. ${ }^{6}$

Participating hospitals were required to have at least 6 years' worth of electronically recorded endoscopy and pathology data for patients undergoing colonic examination prior to the study start (2006). We searched hospital endoscopy databases for patients with colonic examinations before 31 December 2010 and pathology databases for records describing colorectal lesions. We linked and pseudonymised endoscopy and pathology reports and entered them into a database (Oracle Corporation,

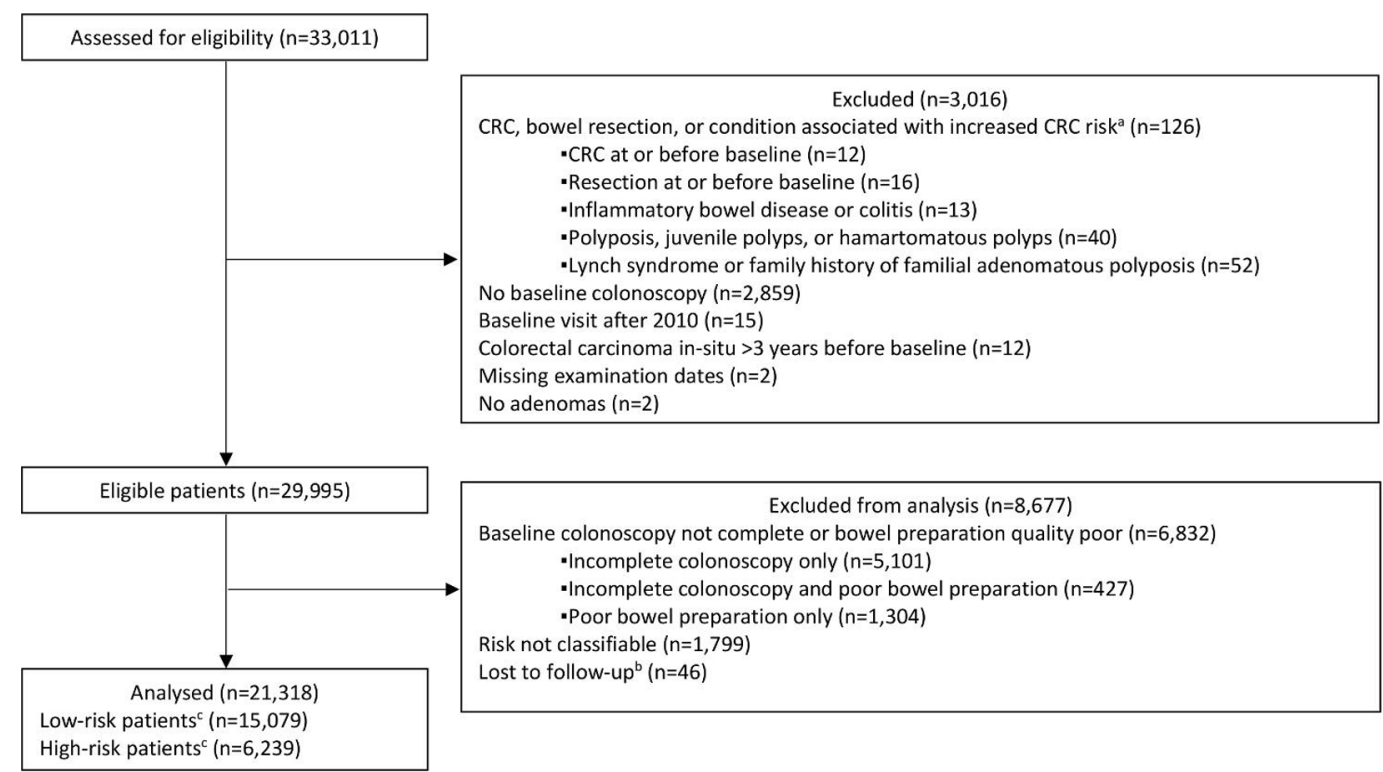

Figure 1 Study profile flow diagram. ${ }^{a}$ Not mutually exclusive. ${ }^{b}$ Reasons for lost to follow-up included having all examinations after emigrating $(n=20)$; having no surveillance and being untraceable through national data sources $(n=22)$; and having an unknown date of birth $(n=4)$. ${ }^{~} H i g h$-risk patients were those with $\geq 2$ premalignant polyps, of which $\geq 1$ was advanced, $\geq 5$ premalignant polyps or $\geq 1$ large $(\geq 20 \mathrm{~mm})$ non-pedunculated premalignant polyp; low-risk patients had none of these findings. CRC, colorectal cancer. 
Table 1 Long-term incidence of colorectal cancer by number of surveillance visits and baseline characteristics $(n=21318)$

\begin{tabular}{|c|c|c|c|c|c|c|c|c|c|}
\hline & $\mathbf{n}$ & $\%$ & $\begin{array}{l}\text { No of person- } \\
\text { years }\end{array}$ & $\begin{array}{l}\text { No of } \\
\text { CRCs }\end{array}$ & $\begin{array}{l}\text { Incidence rate per } \\
100000 \text { person-years } \\
(95 \% \mathrm{Cl})\end{array}$ & $\begin{array}{l}\text { Univariable HR } \\
(95 \% \mathrm{Cl})\end{array}$ & P value* & $\begin{array}{l}\text { Multivariable HR } \\
(95 \% \mathrm{Cl}) \dagger\end{array}$ & P value* \\
\hline Total & 21318 & 100 & 210814 & 368 & 175 (158 to 193$)$ & & & & \\
\hline No of surveillance visitsł & & & & & & & $<0.001$ & & $<0.001$ \\
\hline 0 & 9714 & 45.6 & 116248 & 214 & 184 (161 to 210$)$ & 1 & & 1 & \\
\hline 1 & 5903 & 27.7 & 56923 & 96 & 169 (138 to 206$)$ & 0.72 (0.56 to 0.92$)$ & & 0.65 (0.50 to 0.84$)$ & \\
\hline 2 & 3515 & 16.5 & 25058 & 32 & $128(90$ to 181$)$ & $0.49(0.33$ to 0.71$)$ & & $0.43(0.29$ to 0.63$)$ & \\
\hline$\geq 3$ & 2186 & 10.3 & 12586 & 26 & 207 (141 to 303$)$ & 0.66 (0.43 to 1.03$)$ & & 0.54 (0.35 to 0.85$)$ & \\
\hline Sex & & & & & & & 0.93 & & 0.90 \\
\hline Women & 9022 & 42.3 & 92173 & 161 & 175 (150 to 204) & 1 & & 1 & \\
\hline Men & 12296 & 57.7 & 118641 & 207 & 174 (152 to 200$)$ & $1.01(0.82$ to 1.24$)$ & & $1.01(0.82$ to 1.25$)$ & \\
\hline Age at baseline, years & & & & & & & $<0.001$ & & $<0.001$ \\
\hline$<55$ & 4298 & 20.2 & 51463 & 36 & 70 (50 to 97 ) & 1 & & 1 & \\
\hline $55-64$ & 5956 & 27.9 & 64938 & 77 & 119 (95 to 148$)$ & 1.75 (1.18 to 2.60$)$ & & 1.61 (1.08 to 2.40$)$ & \\
\hline $65-74$ & 6894 & 32.3 & 65186 & 158 & 242 (207 to 283 ) & 3.78 (2.63 to 5.44$)$ & & 3.27 (2.27 to 4.72$)$ & \\
\hline$\geq 75$ & 4170 & 19.6 & 29228 & 97 & 332 (272 to 405$)$ & 5.66 (3.84 to 8.34$)$ & & 4.31 (2.91 to 6.38$)$ & \\
\hline No of PMPs & & & & & & & $<0.001$ & & 0.003 \\
\hline 1 & 12231 & 57.4 & 124117 & 163 & 131 (113 to 153$)$ & 1 & & 1 & \\
\hline 2 & 4714 & 22.1 & 45601 & 100 & 219 (180 to 267 ) & 1.70 (1.33 to 2.18$)$ & & 1.36 (1.07 to 1.71$)$ & \\
\hline 3 & 2035 & 9.6 & 19482 & 41 & 210 (155 to 286$)$ & 1.63 (1.16 to 2.30$)$ & & & \\
\hline 4 & 951 & 4.5 & 8856 & 23 & 260 (173 to 391$)$ & 2.02 (1.31 to 3.13$)$ & & & \\
\hline$\geq 5$ & 1387 & 6.5 & 12760 & 41 & 321 (237 to 436) & 2.53 (1.79 to 3.56$)$ & & 1.82 (1.25 to 2.66$)$ & \\
\hline PMP size, mm§ & & & & & & & $<0.001$ & & 0.46 \\
\hline$<10$ & 11553 & 54.2 & 116281 & 166 & 143 (123 to 166$)$ & 1 & & 1 & \\
\hline $10-19$ & 6081 & 28.5 & 59382 & 109 & 184 (152 to 221$)$ & 1.29 (1.01 to 1.64$)$ & & $1.06(0.81$ to 1.38$)$ & \\
\hline$\geq 20$ & 3625 & 17.0 & 34544 & 92 & 266 (217 to 327 ) & 1.87 (1.45 to 2.42 ) & & 1.28 (0.93 to 1.76$)$ & \\
\hline Unknown & 59 & 0.3 & 607 & 1 & 165 (23 to 1169$)$ & 1.11 (0.16 to 7.92$)$ & & 0.69 (0.10 to 5.03$)$ & \\
\hline Adenoma histology & & & & & & & $<0.001$ & & $<0.001$ \\
\hline Tubular & 12786 & 60.0 & 127882 & 171 & 134 (115 to 155$)$ & 1 & & 1 & \\
\hline Tubulovillous & 6480 & 30.4 & 62187 & 137 & 220 (186 to 260$)$ & 1.66 (1.33 to 2.08$)$ & & $1.42(1.12$ to 1.80$)$ & \\
\hline Villous & 1045 & 4.9 & 9958 & 31 & 311 (219 to 443 ) & 2.35 (1.61 to 3.45 ) & & 1.60 (1.07 to 2.40$)$ & \\
\hline Unknown & 1007 & 4.7 & 10787 & 29 & 269 (187 to 387) & 1.94 (1.31 to 2.88$)$ & & 2.06 (1.37 to 3.11$)$ & \\
\hline Adenoma dysplasia** & & & & & & & $<0.001$ & & 0.03 \\
\hline Low grade & 18592 & 87.2 & 183696 & 290 & 158 (141 to 177) & 1 & & 1 & \\
\hline High grade & 2148 & 10.1 & 19913 & 63 & 316 (247 to 405 ) & 2.03 (1.54 to 2.66$)$ & & 1.51 (1.12 to 2.02$)$ & \\
\hline Unknown & 578 & 2.7 & 7206 & 15 & 208 (125 to 345$)$ & 1.22 (0.72 to 2.06$)$ & & 1.22 (0.71 to 2.11 ) & \\
\hline Proximal polypst† & & & & & & & $<0.001$ & & $<0.001$ \\
\hline No & 11566 & 54.3 & 118513 & 152 & 128 (109 to 150$)$ & 1 & & 1 & \\
\hline Yes & 9752 & 45.8 & 92301 & 216 & 234 (205 to 267 ) & 1.86 (1.51 to 2.29$)$ & & 1.63 (1.30 to 2.05$)$ & \\
\hline Year of baseline visit & & & & & & & 0.81 & & 0.34 \\
\hline 1984-1999 & 2057 & 9.7 & 28319 & 60 & 212 (165 to 273 ) & 1 & & 1 & \\
\hline 2000-2004 & 6651 & 31.2 & 74494 & 137 & 184 (156 to 217 ) & $0.96(0.69$ to 1.34$)$ & & $0.89(0.64$ to 1.23$)$ & \\
\hline $2005-2010$ & 12610 & 59.2 & 108001 & 171 & 158 (136 to 184$)$ & 0.91 (0.65 to 1.27$)$ & & 0.78 (0.56 to 1.10$)$ & \\
\hline Length of baseline visit, days & & & & & & & $<0.001$ & & 0.04 \\
\hline 1 & 14223 & 66.7 & 140884 & 208 & 148 (129 to 169$)$ & 1 & & 1 & \\
\hline $2-90$ & 3035 & 14.2 & 29429 & 70 & 238 (188 to 301$)$ & 1.63 (1.24 to 2.13$)$ & & 1.50 (1.13 to 1.99$)$ & \\
\hline $91-183$ & 2085 & 9.8 & 21071 & 43 & 204 (151 to 275$)$ & 1.38 (0.99 to 1.92$)$ & & 1.21 (0.86 to 1.71$)$ & \\
\hline$\geq 184$ & 1975 & 9.3 & 19430 & 47 & 242 (182 to 322 ) & 1.63 (1.19 to 2.24$)$ & & 1.30 (0.92 to 1.82$)$ & \\
\hline Family history of cancer/CRC $\ddagger \ddagger$ & & & & & & & 0.22 & & 0.10 \\
\hline No & 19730 & 92.6 & 191764 & 340 & 177 (159 to 197$)$ & 1 & & 1 & \\
\hline Yes & 1588 & 7.5 & 19051 & 28 & 147 (101 to 213$)$ & 0.79 (0.54 to 1.16$)$ & & $1.42(0.95$ to 2.11$)$ & \\
\hline
\end{tabular}

${ }^{*} \mathrm{P}$ values were calculated with the likelihood ratio test.

tThe final multivariable model contained number of surveillance visits, age, number of PMPs, adenoma histology, adenoma dysplasia, proximal polyps and length of baseline visit. For these variables, the multivariable HRs were from the final multivariable model and the $\mathrm{p}$ values were for inclusion of the variable in the model. For the remaining variables, the multivariable HRs were for if the variable was added as an additional variable to the final multivariable model.

‡Number of surveillance visits was included as a time-varying covariate, meaning that patients who had surveillance contributed person-years to more than a single category of number of surveillance visits. §PMP size was defined according to the largest PMP seen at baseline.

IAdenoma histology was defined according to the greatest degree of villousness seen at baseline.

**Adenoma dysplasia was defined according to the highest grade of dysplasia seen at baseline.

††Proximal polyps were defined as those proximal to the descending colon.

‡¥Family history of cancer/CRC was defined as 'family history of cancer or CRC reported at an examination before or during visit'. Of cases with a 'family history of cancer', $72 \%$ were from a specialist hospital for colorectal diseases and so we assumed these cases had a family history of CRC.

CRC, colorectal cancer; mm, millimetre; PMP, premalignant polyp. 

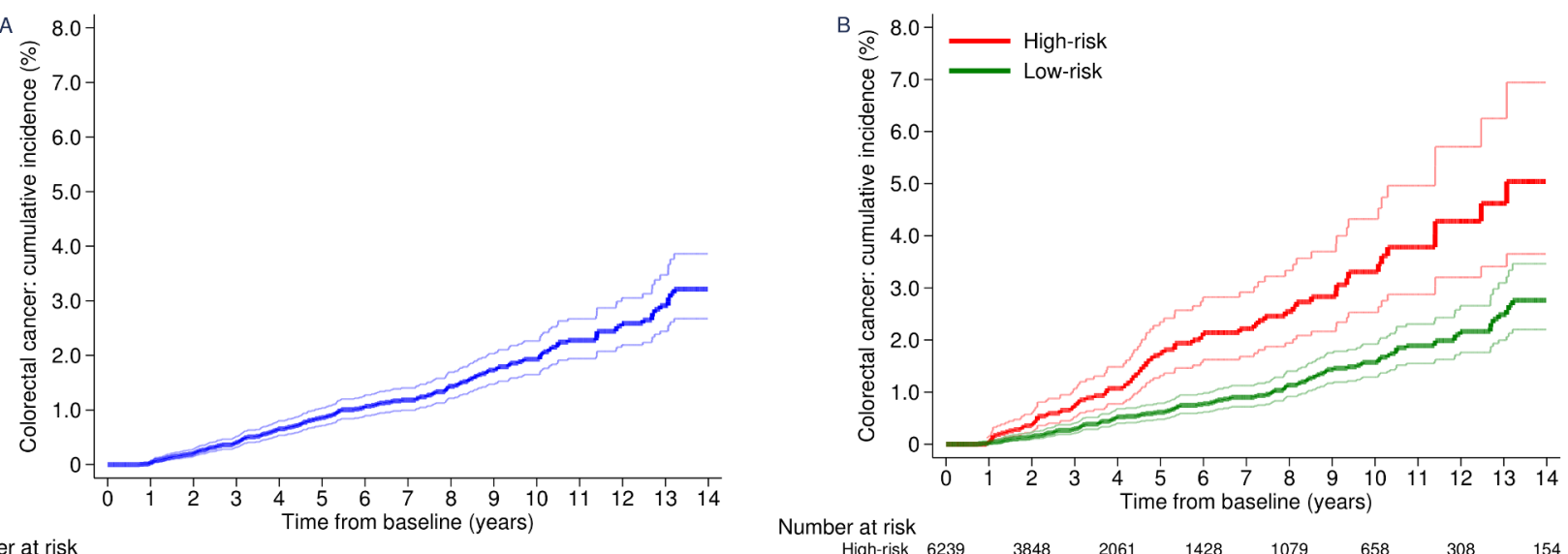

Number at risk
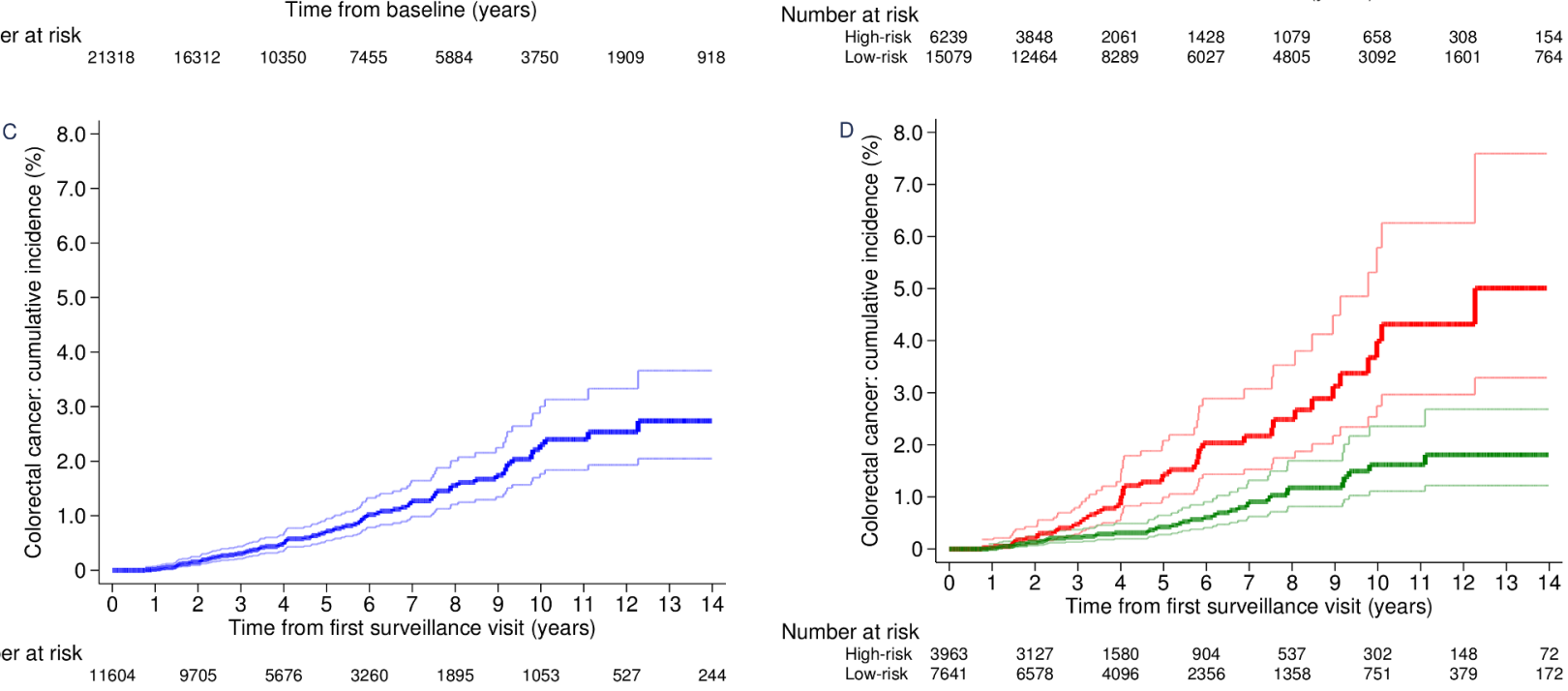

Number at risk

Number at risk

$\begin{array}{lllllclll}\text { High-risk } & 3963 & 3127 & 1580 & 904 & 537 & 302 & 148 & 72 \\ \text { Low-risk } & 7641 & 6578 & 4096 & 2356 & 1358 & 751 & 379 & 172\end{array}$
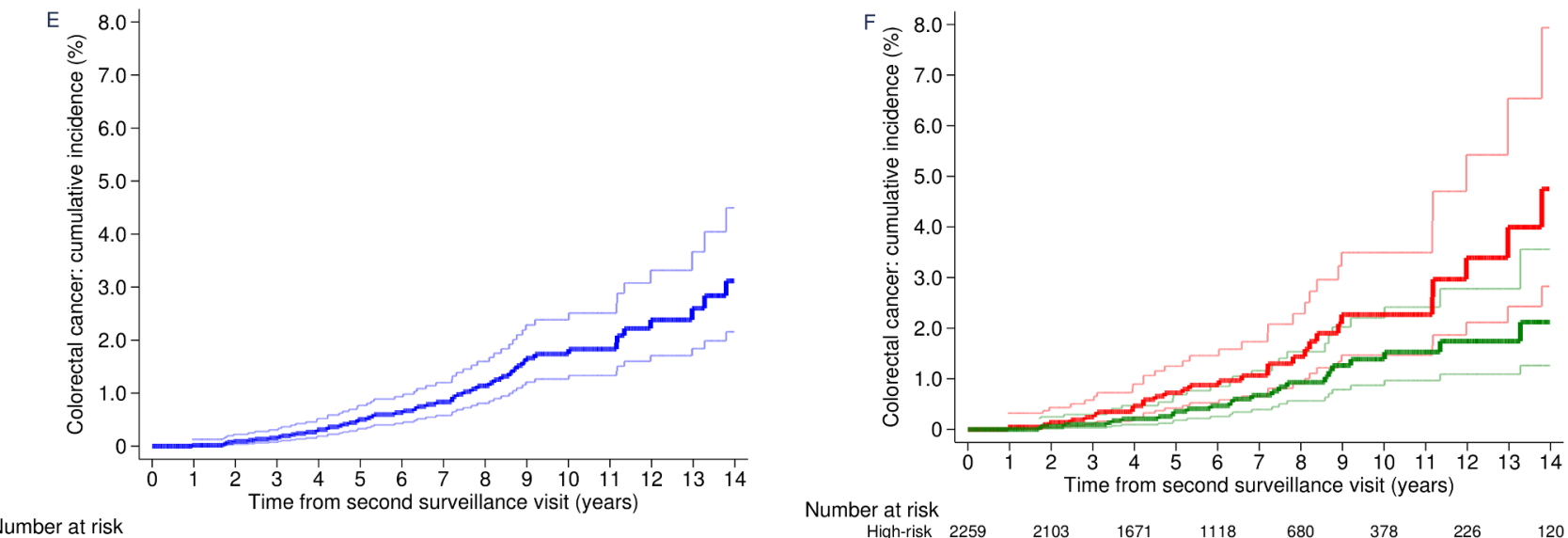

Number at risk

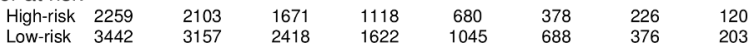

Figure 2 Cumulative incidence of colorectal cancer by time from baseline, first surveillance and second surveillance. Cumulative incidence of colorectal cancer without surveillance (censoring at any first surveillance visit) for the whole cohort (A) and for low-risk and high-risk patients (B). Cumulative incidence of colorectal cancer after first surveillance (censoring at any second surveillance visit) for the whole cohort (C) and for low-risk and high-risk patients (D). Cumulative incidence of colorectal cancer after second surveillance (censoring at end of follow-up) for the whole cohort (E) and for low-risk and high-risk patients (F). 95\% Cls are shown for each curve. High-risk patients were those with $\geq 2$ premalignant polyps, of which $\geq 1$ was advanced, $\geq 5$ premalignant polyps or $\geq 1$ large $(\geq 20 \mathrm{~mm}$ ) non-pedunculated premalignant polyp; low-risk patients had none of these findings.

Redwood City, California, USA). We assigned summary values for size, histology and location to lesions seen at $>1$ examination. ${ }^{10}$

Once we had identified patients with colonic examinations before 31 December 2010, we examined their records to identify the first adenoma diagnosis, which we defined as 'baseline'. In some cases, $>1$ examination was required at baseline to completely examine the colon and remove all detected lesions; we grouped these examinations into the 'baseline visit'. Baseline visits could extend over multiple days. We grouped colonic examinations occurring after the baseline visit into surveillance visits. ${ }^{10}$ We collected data on colonic examinations through 2016.

To be included, patients were required to have had a colonoscopy and $\geq 1$ adenomas at baseline. We excluded patients 
Table 2 Cumulative incidence of colorectal cancer and age-sex-standardised incidence ratios in the whole cohort $(n=21318)$

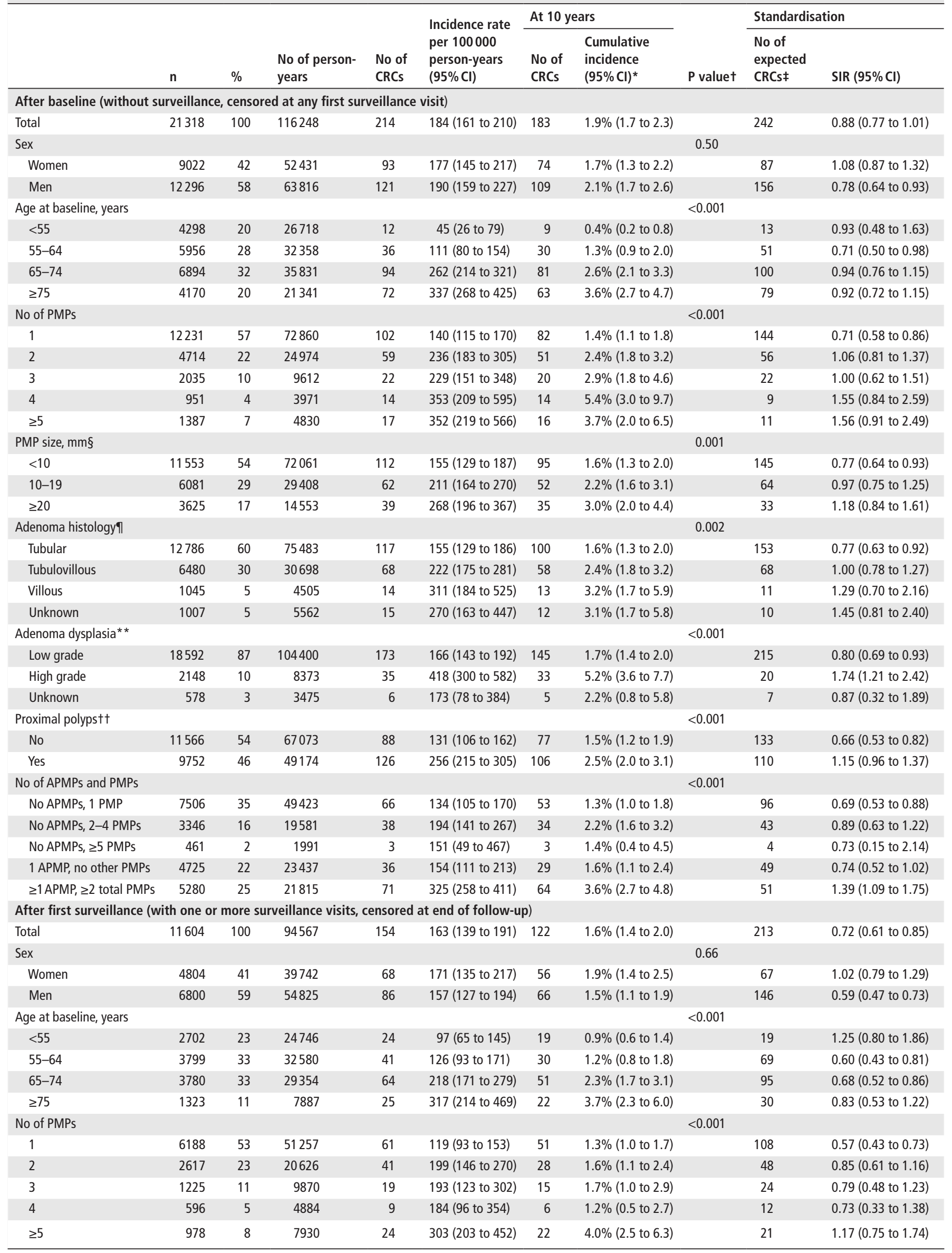


Table 2 Continued

\begin{tabular}{|c|c|c|c|c|c|c|c|c|c|c|}
\hline & \multirow[b]{2}{*}{$\mathrm{n}$} & \multirow[b]{2}{*}{$\%$} & \multirow[b]{2}{*}{$\begin{array}{l}\text { No of person- } \\
\text { years }\end{array}$} & \multirow[b]{2}{*}{$\begin{array}{l}\text { No of } \\
\text { CRCs }\end{array}$} & \multirow{2}{*}{$\begin{array}{l}\text { Incidence rate } \\
\text { per } 100000 \\
\text { person-years } \\
(95 \% \mathrm{Cl})\end{array}$} & \multicolumn{2}{|c|}{ At 10 years } & \multirow[b]{2}{*}{$P$ valuet } & \multicolumn{2}{|c|}{ Standardisation } \\
\hline & & & & & & $\begin{array}{l}\text { No of } \\
\text { CRCs }\end{array}$ & $\begin{array}{l}\text { Cumulative } \\
\text { incidence } \\
(95 \% \mathrm{Cl})^{*}\end{array}$ & & $\begin{array}{l}\text { No of } \\
\text { expected } \\
\text { CRCs } \neq\end{array}$ & SIR $(95 \% \mathrm{Cl})$ \\
\hline PMP size, mm§ & & & & & & & & $<0.001$ & & \\
\hline$<10$ & 5608 & 48 & 44221 & 54 & 122 (94 to 159) & 44 & $1.3 \%(0.9$ to 1.7$)$ & & 93 & 0.58 (0.43 to 0.75$)$ \\
\hline $10-19$ & 3591 & 31 & 29974 & 47 & 157 (118 to 209) & 39 & $1.5 \%$ (1.1 to 2.1$)$ & & 70 & 0.67 (0.50 to 0.90$)$ \\
\hline$\geq 20$ & 2366 & 20 & 19991 & 53 & 265 (203 to 347) & 39 & $2.7 \%$ (1.9 to 3.7$)$ & & 48 & $1.10(0.82$ to 1.44$)$ \\
\hline Adenoma histology & & & & & & & & $<0.001$ & & \\
\hline Tubular & 6526 & 56 & 52399 & 54 & 103 (79 to 135$)$ & 42 & $0.9 \%(0.7$ to 1.3$)$ & & 114 & 0.48 (0.36 to 0.62$)$ \\
\hline Tubulovillous & 3849 & 33 & 31489 & 69 & 219 (173 to 277$)$ & 57 & $2.4 \%$ (1.8 to 3.2$)$ & & 74 & 0.94 (0.73 to 1.19$)$ \\
\hline Villous & 660 & 6 & 5453 & 17 & 312 (194 to 501) & 13 & $3.0 \%(1.7$ to 5.5$)$ & & 14 & 1.21 (0.70 to 1.93$)$ \\
\hline Unknown & 569 & 5 & 5225 & 14 & 268 (159 to 452 ) & 10 & $2.6 \%(1.4$ to 5.0$)$ & & 11 & 1.23 (0.67 to 2.06$)$ \\
\hline Adenoma dysplasia** & & & & & & & & 0.05 & & \\
\hline Low grade & 9857 & 85 & 79296 & 117 & 148 (123 to 177$)$ & 92 & $1.5 \%(1.2$ to 1.8$)$ & & 175 & 0.67 (0.55 to 0.80$)$ \\
\hline High grade & 1389 & 12 & 11539 & 28 & 243 (168 to 351 ) & 25 & $2.7 \%(1.8$ to 4.1$)$ & & 29 & 0.95 (0.63 to 1.38 ) \\
\hline Unknown & 358 & 3 & 3731 & 9 & 241 (126 to 464$)$ & 5 & $1.8 \%(0.7$ to 4.3$)$ & & 8 & 1.10 (0.50 to 2.09 ) \\
\hline Proximal polypst† & & & & & & & & $<0.001$ & & \\
\hline No & 6195 & 53 & 51440 & 64 & 124 (97 to 159) & 50 & $1.2 \%(0.9$ to 1.7$)$ & & 109 & 0.59 (0.45 to 0.75$)$ \\
\hline Yes & 5409 & 47 & 43126 & 90 & 209 (170 to 257$)$ & 72 & $2.1 \%$ (1.7 to 2.7$)$ & & 103 & 0.87 (0.70 to 1.07$)$ \\
\hline No of APMPs and PMPs & & & & & & & & $<0.001$ & & \\
\hline No APMPs, 1 PMP & 3402 & 29 & 26997 & 27 & 100 (69 to 146) & 23 & $1.1 \%(0.7$ to 1.7$)$ & & 54 & 0.50 (0.33 to 0.73 ) \\
\hline No APMPs, 2-4 PMPs & 1748 & 15 & 13362 & 17 & 127 (79 to 205 ) & 11 & $1.0 \%(0.5$ to 1.9$)$ & & 30 & 0.57 (0.33 to 0.91$)$ \\
\hline No APMPs, $\geq 5$ PMPs & 310 & 3 & 2566 & 6 & 234 (105 to 520$)$ & 6 & $3.1 \%$ (1.4 to 7.2$)$ & & 6 & 0.95 (0.35 to 2.06$)$ \\
\hline 1 APMP, no other PMPs & 2786 & 24 & 24259 & 34 & 140 (100 to 196$)$ & 28 & $1.5 \%(1.0$ to 2.2$)$ & & 54 & 0.64 (0.44 to 0.89 ) \\
\hline$\geq 1 \mathrm{APMP}, \geq 2$ total PMPs & 3358 & 29 & 27382 & 70 & 256 (202 to 323$)$ & 54 & $2.4 \%$ (1.8 to 3.3$)$ & & 69 & 1.02 (0.79 to 1.29 ) \\
\hline
\end{tabular}

${ }^{*}$ Cumulative CRC incidence was estimated using the Kaplan-Meier method.

†P values were calculated with the log-rank test to compare cumulative CRC incidence among each category of the specified variable.

¥Numbers of expected CRCs were calculated by multiplying the 5-year age-group and sex-specific observed person-years by the corresponding CRC incidence rates in the general population of England in 2007.

§PMP size was defined according to the largest PMP seen at baseline. Patients with PMPs of unknown size are not included in the table; in the analyses without surveillance, there were 59 such patients, of whom one was diagnosed with CRC; and in the analyses with one or more surveillance visits, there were 39 such patients with no CRC cases.

ПAdenoma histology was defined according to the greatest degree of villousness seen at baseline.

${ }^{* *}$ Adenoma dysplasia was defined according to the highest grade of dysplasia seen at baseline.

t†Proximal polyps were defined as those proximal to the descending colon.

APMP, advanced PMP; CRC, colorectal cancer; PMP, premalignant polyp; SIR, standardised incidence ratio.

with CRC or a bowel resection at or before baseline; inflammatory bowel disease or colitis; Lynch syndrome or family history of familial adenomatous polyposis; polyposis, juvenile polyps or hamartomatous polyps; colorectal carcinoma in situ (now described as high-grade dysplasia) reported in registry data $>3$ years before baseline, which we thought had the potential to progress to invasive carcinoma by baseline; an examination without a recorded date; or were missing information required for risk classification.

We additionally excluded patients whose baseline colonoscopy was suboptimal (incomplete or of unknown completeness, or with poor bowel preparation) so that our data reflect contemporary high-quality colonoscopy practice. Suboptimal baseline colonoscopies were associated with increased CRC risk in our previous studies of this cohort. ${ }^{9} 1018$

Data on cancers and deaths were provided by the National Health Service (NHS) Central Register, National Services Scotland and NHS Digital through 2016 (Scotland) or 2017 (England). We compared the cancer data with the pathology data on the database and resolved duplicate and inconsistent records.

The primary outcome was incident adenocarcinoma of the colorectum. This included cancers with unspecified morphology if they were located between the caecum and rectum, but not if they were located around the anus; we assumed the former were adenocarcinomas, the latter squamous cell carcinomas. In-situ cancers were not included.

We excluded CRCs that we assumed had developed from incompletely excised baseline lesions $(n=25)$; those found in the same/neighbouring colonic segment to an adenoma measuring $\geq 15 \mathrm{~mm}$ at baseline and seen at least twice within 5 years before the cancer diagnosis. ${ }^{9} 1018$ We did this so that our data reflect current practice, considering the improvements in quality of endoscopic excision over the past decade. ${ }^{19}$ In a sensitivity analysis, we did not make this exclusion.

We classified patients into 'low-risk' and 'high-risk' groups based on the 2020 UK guidelines. ${ }^{6}$ High-risk patients were those with $\geq 2$ PMPs, of which $\geq 1$ was 'advanced' (adenoma $\geq 10 \mathrm{~mm}$ or with high-grade dysplasia; serrated polyp $\geq 10 \mathrm{~mm}$ or with dysplasia); $\geq 5$ PMPs; or $\geq 1$ LNPPMP. Patients without these findings were classified as low risk.

We did not create separate serrated polyp variables because serrated polyps were not consistently recorded or classified in the era of our data, and patients in our cohort with serrated polyps were a selected subgroup of patients with both adenomas and serrated polyps at baseline. However, we used any available serrated polyp data in our classification of risk (ie, in the count of PMPs and advanced PMPs). Our definition of serrated polyps included hyperplastic polyps and sessile-serrated lesions. 
In the 2020 UK guidelines, serrated polyps also include serrated adenomas and mixed hyperplastic-adenomatous polyps ${ }^{6}$; however, these would likely have been recorded as adenomas in the age of our data and so we included them as such. ${ }^{9} 1018$

\section{Statistical analysis}

We used $\chi^{2}$ tests to compare baseline characteristics among patients with and without surveillance visits, and among lowrisk and high-risk patients.

We performed the following analyses for the whole cohort and both risk groups. We estimated long-term CRC incidence after polypectomy. Time-at-risk started from the latest examination at baseline. We censored time-to-event data at first CRC diagnosis, emigration, death or the date cancer registration data was considered complete. Exposure to successive surveillance visits started at the latest examination in each visit. We did not include visits at which CRC was diagnosed as surveillance visits because they offered no protection against CRC. We divided each patient's follow-up time into three periods: without surveillance, censoring at any first surveillance; after first surveillance, censoring at any second surveillance; and after second surveillance, censoring at end of follow-up. For the whole cohort and low-risk group, we combined the last two periods in some analyses to estimate CRC incidence in the presence of $\geq 1$ surveillance visits.

We examined effects of baseline characteristics and surveillance on CRC incidence using univariable and multivariable Cox proportional hazards models to estimate HRs with 95\% CIs. Baseline characteristics of interest included sex, age, number and size of PMPs, adenoma histology and dysplasia, proximal polyps, year of baseline visit, length of baseline visit (in days) and family history of cancer/CRC. We identified independent CRC risk factors in the whole cohort in multivariable models using backward stepwise selection to retain variables with $\mathrm{p}$ values $<0.05$ in likelihood ratio tests. We included number of surveillance visits as a time-varying covariate. As we excluded patients with poor bowel preparation from this analysis, we do not present CRC incidence by bowel preparation quality because we previously showed that CRC incidence is similar among the remaining categories ('excellent or good', 'satisfactory', and 'unknown'). ${ }^{9}$

We performed Kaplan-Meier analyses to show time to CRC diagnosis and estimate cumulative CRC incidence at 10 years with $95 \%$ CIs. We compared cumulative incidence curves using the log-rank test. We calculated standardised incidence ratios (SIRs) with exact Poisson 95\% CIs, dividing the observed by the expected number of CRC cases. We estimated expected cases by multiplying sex-specific and 5-year age-group-specific personyears with the corresponding CRC incidence in the general population of England in 2007 (approximately the middle of the follow-up period).$^{20}$ As the need for surveillance is determined by comparing CRC incidence without surveillance to that in the general population, ${ }^{6}$ our analysis of SIRs in the absence of surveillance was the main focus of our study.

We performed analyses in Stata/IC V.13.1. ${ }^{21}$ The study is registered (ISRCTN15213649). The protocol is available online. ${ }^{22}$

\section{RESULTS}

The cohort included 33011 patients. Of these, we excluded 126 with CRC or a bowel resection at or before baseline or a condition associated with increased CRC risk; 2859 without a baseline colonoscopy; 15 with a baseline visit after 2010; 12 with colorectal carcinoma in situ reported in registry data $>3$ years before baseline; 2 with missing examination dates; 2 with no adenomas; 1799 who were missing information needed for risk classification; 6832 whose baseline colonoscopy was not complete or bowel preparation quality was poor; and 46 who were lost to follow-up. This left 21318 for analysis (figure 1).

In the whole cohort, the median age was 65 years (IQR $57-72$ ), $42 \%$ were female and $54 \%$ attended $\geq 1$ surveillance visits (table 1). The median time from baseline to first surveillance was 3.0 years (IQR 1.5-4.1). Patients attending surveillance $(n=11604)$ were younger than non-attenders $(n=9714)$ and more likely to have had, at baseline, a greater number of PMPs, PMPs $\geq 10 \mathrm{~mm}$, adenomas with tubulovillous/villous histology or high-grade dysplasia, proximal polyps, a baseline visit before 2005, a baseline visit spanning $>1$ day, a family history of cancer/CRC or missing data (online supplemental table 1).

Over a median follow-up of 10.1 years (IQR 7.5-12.7), 368 CRCs were diagnosed, giving an incidence rate of 175 per 100000 person-years (95\% CI 158 to 193). Attendance at $\geq 1$ surveillance visits was independently associated with reduced CRC incidence, while age $\geq 55$ years and having $\geq 2$ PMPs, an adenoma with tubulovillous/villous/unknown histology or highgrade dysplasia, proximal polyps or a baseline visit spanning 2-90 days were independently associated with increased CRC incidence (table 1).

Without surveillance, in the whole cohort, cumulative CRC incidence at 10 years was $1.9 \%$ (95\% CI $1.7 \%$ to $2.3 \%$ ) (table 2; figure $2 \mathrm{~A}$ ) and CRC incidence was similar to that in the general population (SIR $0.88,95 \%$ CI 0.77 to 1.01) (table 2). Incidence of CRC was lower than in the general population among men (SIR 0.78, 95\% CI 0.64 to 0.93), patients aged 55-64 years $(0.71,0.50$ to 0.98$)$, and patients with a single PMP $(0.71,0.58$ to 0.86$)$, PMPs $<10 \mathrm{~mm}(0.77,0.64$ to 0.93$)$, adenomas with tubular histology $(0.77,0.63$ to 0.92$)$, adenomas with low-grade dysplasia $(0.80,0.69$ to 0.93$)$ or no proximal polyps $(0.66,0.53$ to 0.82 ) at baseline. In contrast, CRC incidence without surveillance was higher among patients with adenomas with high-grade dysplasia (SIR 1.74, 95\% CI 1.21 to 2.42 ) or $\geq 2$ PMPs, of which $\geq 1$ was advanced $(1.39,1.09$ to 1.75$)$ than in the general population (table 2).

In the presence of $\geq 1$ surveillance visits, cumulative CRC incidence in the whole cohort was $1.6 \%$ (95\% CI $1.4 \%$ to $2.0 \%)$ at 10 years (table 2; figure 2C). Incidence of CRC among all patients was lower than in the general population (SIR 0.72, $95 \%$ CI 0.61 to 0.85 ) and no longer significantly higher among those with adenomas with high-grade dysplasia (SIR 0.95, 95\% CI 0.63 to 1.38 ) or $\geq 2$ PMPs, of which $\geq 1$ was advanced (1.02, 0.79 to 1.29 ) (table 2 ).

\section{Low-risk and high-risk groups}

We then classified patients into low-risk $(\mathrm{n}=15079,71 \%)$ and high-risk $(n=6239,29 \%)$ groups (tables $3-5) .{ }^{6}$

Among low-risk patients, the median age was 64 years (IQR $55-72$ ), $45 \%$ were female (table 4 ) and $51 \%$ attended $\geq 1$ surveillance visits (table 3). The median time from baseline to first surveillance was 3.1 years (IQR 2.1-4.9). Over a median follow-up of 10.3 years (IQR 7.7-12.9), 206 CRCs were diagnosed, giving an incidence rate of 135 per 100000 person-years (95\% CI 118 to 155) (table 3).

Among high-risk patients, the median age was 67 years (IQR 60-73), 36\% were female (table 5) and $64 \%$ attended $\geq 1$ surveillance visits (table 3 ). The median time from baseline to first surveillance was 2.1 years (IQR 1.1-3.2). Over a median 
Table 3 Effects of surveillance on colorectal cancer incidence by number of surveillance visits and risk group

\begin{tabular}{|c|c|c|c|c|c|c|c|c|c|}
\hline & \multirow[b]{2}{*}{$\mathbf{n}$} & \multirow[b]{2}{*}{$\%$} & \multirow[b]{2}{*}{$\begin{array}{l}\text { No of person- } \\
\text { years }\end{array}$} & \multirow[b]{2}{*}{$\begin{array}{l}\text { No of } \\
\text { CRCs }\end{array}$} & \multirow[b]{2}{*}{$\begin{array}{l}\text { Incidence rate per } 100000 \\
\text { person-years }(95 \% \mathrm{Cl})\end{array}$} & \multicolumn{4}{|c|}{ Effect of surveillance on CRC incidence* } \\
\hline & & & & & & $\begin{array}{l}\text { Univariable HR } \\
(95 \% \mathrm{Cl})\end{array}$ & $P$ valuet & $\begin{array}{l}\text { Multivariable HR } \\
(95 \% \mathrm{Cl}) \ddagger\end{array}$ & $P$ valuet \\
\hline Low-risk patients§ & & & & & & & $<0.001$ & & 0.001 \\
\hline 0 visit & 7438 & 49.3 & 90451 & 136 & 150 (127 to 178$)$ & 1 & & 1 & \\
\hline 1 visit & 4199 & 27.8 & 39392 & 44 & 112 (83 to 150$)$ & 0.57 (0.40 to 0.81$)$ & & 0.58 (0.41 to 0.83 ) & \\
\hline$\geq 2$ visits & 3442 & 22.8 & 22654 & 26 & 115 (78 to 169$)$ & 0.48 (0.30 to 0.75$)$ & & 0.53 (0.33 to 0.83$)$ & \\
\hline Total & 15079 & 70.7 & 152497 & 206 & 135 (118 to 155$)$ & & & & \\
\hline High-risk patients§ & & & & & & & $<0.001$ & & 0.002 \\
\hline 0 visit & 2276 & 36.5 & 25796 & 78 & 302 (242 to 377 ) & 1 & & 1 & \\
\hline 1 visit & 1704 & 27.3 & 17531 & 52 & 297 (226 to 389) & 0.73 (0.51 to 1.05 ) & & 0.71 (0.49 to 1.03 ) & \\
\hline$\geq 2$ visits & 2259 & 36.2 & 14990 & 32 & 213 (151 to 302 ) & 0.42 (0.27 to 0.66$)$ & & 0.44 ( 0.28 to 0.70$)$ & \\
\hline Total & 6239 & 29.3 & 58318 & 162 & 278 (238 to 324$)$ & & & & \\
\hline
\end{tabular}

${ }^{*}$ Number of surveillance visits was included as a time-varying covariate, meaning that patients who had surveillance contributed person-years to more than a single category of number of surveillance visits.

tP values were calculated with the likelihood ratio test.

‡Multivariable HR adjusted for age, number of premalignant polyps, adenoma histology, adenoma dysplasia, proximal polyps and length of baseline visit, the characteristics independently associated with CRC incidence in the whole cohort.

§High-risk patients were those with $\geq 2$ premalignant polyps, of which $\geq 1$ was advanced, $\geq 5$ premalignant polyps, or $\geq 1$ large $(\geq 20$ mm) non-pedunculated premalignant polyp; low-risk patients had none of these findings.

$\mathrm{CRC}$, colorectal cancer.

follow-up of 9.6 years (IQR 6.5-12.1), 162 CRCs were diagnosed, giving an incidence rate of 278 per 100000 person-years (95\% CI 238 to 324) (table 3). The two risk groups differed significantly on all baseline characteristics and high-risk patients had more surveillance than low-risk patients (online supplemental table 2).

In both risk groups, surveillance was associated with reduced CRC incidence. Among low-risk patients, CRC incidence was lower with $\geq 1$ surveillance visits than with none, adjusting for characteristics associated with CRC incidence in the whole cohort (HR $0.58,95 \%$ CI 0.41 to 0.83 for 1 visit; $0.53,0.33$ to 0.83 for $\geq 2$ visits). A similar pattern was observed for high-risk patients (HR $0.71,95 \%$ CI 0.49 to 1.03 for 1 visit; $0.44,0.28$ to 0.70 for $\geq 2$ visits), although the CI of the HR for a single visit included one (table 3 ).

Among low-risk patients, without surveillance, cumulative CRC incidence at 10 years was $1.6 \%$ (95\% CI $1.3 \%$ to $1.9 \%)$ (table 4; figure 2B) and CRC incidence was lower than in the general population (SIR 0.75, 95\% CI 0.63 to 0.88 ). The CIs of all SIRs were below or crossed one, showing that CRC incidence was not elevated by any baseline characteristic (table 4).

Among high-risk patients, without surveillance, cumulative CRC incidence at ten years was 3.3\% (95\% CI 2.5\% to $4.3 \%$ ) (table 5; figure 2B) and CRC incidence was higher than in the general population (SIR 1.30, 95\% CI 1.03 to 1.62) (table 5). Examining SIRs by baseline characteristics, CRC incidence without surveillance was higher than in the general population among women (SIR 1.79, 95\% CI 1.23 to 2.51 ) and those with PMPs $\geq 20 \mathrm{~mm}$ (1.52, 1.06 to 2.11$)$, adenomas with high-grade dysplasia $(2.28,1.52$ to 3.27$)$, or proximal polyps $(1.52,1.14$ to 1.99) at baseline (table 5).

After a single surveillance visit, among high-risk patients, cumulative CRC incidence at 10 years was 4.0\% (95\% CI $2.8 \%$ to $5.8 \%$ ) (table 5; figure 2D); higher than without surveillance, likely because the cohort had aged. Incidence of CRC was no longer significantly higher than in the general population (SIR $1.22,95 \%$ CI 0.91 to 1.60 ). Examining SIRs by baseline characteristics, CRC incidence was higher than in the general population among women (SIR 1.67, 95\% CI 1.00 to 2.61) and those aged $<55$ years $(4.26,1.84$ to 8.39$)$; however, these estimates were based on few CRC cases (table 5). After second surveillance, the CIs of all SIRs included one (table 5).

Results followed the same pattern when we did not exclude CRCs assumed to have arisen from incompletely excised baseline lesions. For some baseline polyp characteristics, there were slight changes to the associated $\mathrm{p}$ values in our analyses of CRC incidence or SIRs such that they became significant; for example, in the whole cohort, presence of $\geq 4$ PMPs, PMPs $\geq 20 \mathrm{~mm}$, adenomas with villous histology and proximal polyps became associated with elevated SIRs in the absence of surveillance, while in high-risk patients, this was seen for $\geq 4$ PMPs and adenomas with tubulovillous/villous histology (online supplemental tables 3-7).

\section{DISCUSSION}

This study provides unique data on long-term post-polypectomy CRC incidence by baseline characteristics and a vitally important examination of the 2020 UK surveillance guidelines. Through investigation of 21318 patients who underwent colonoscopy with polypectomy and were followed-up for a median of 10.1 years, we found that CRC incidence in most patients was similar to or lower than that in the general population. We demonstrated that the new UK guidelines are accurate at identifying and discriminating between those at increased risk of CRC who require surveillance, and those at low risk who can be managed by population-based non-invasive CRC screening instead. ${ }^{6}$

We identified several baseline risk factors for CRC, including older age ( $\geq 55$ years) and presence of multiple $(\geq 2)$ PMPs, adenomas with tubulovillous/villous/unknown histology or highgrade dysplasia, proximal polyps and a baseline visit spanning 2-90 days. This is in line with our previous studies which found associations between these factors and increased CRC incidence when this same cohort was stratified into risk groups following the 2002 UK guidelines, ${ }^{9} 1018$ and other studies describing these as risk factors for metachronous advanced neoplasia. ${ }^{6}$ However, compared with the general population, CRC incidence was higher only among those with adenomas with high-grade dysplasia or 
Table 4 Cumulative incidence of colorectal cancer and age-sex-standardised incidence ratios in low-risk patients $(n=15079)$

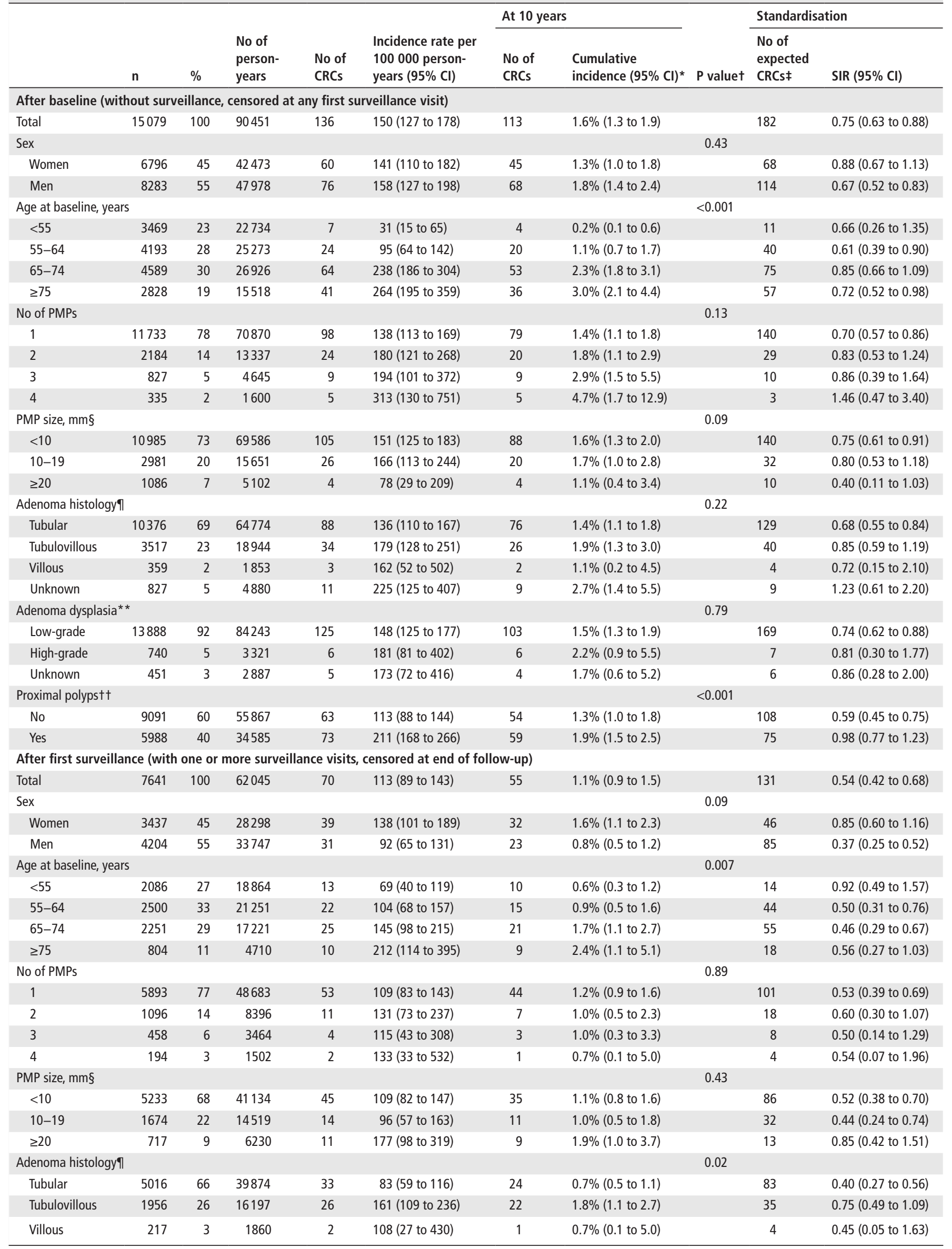




\begin{tabular}{|c|c|c|c|c|c|c|c|c|c|c|}
\hline \multirow[b]{2}{*}{$\mathrm{n}$} & \multirow[b]{2}{*}{ n } & \multirow[b]{2}{*}{$\%$} & \multirow[b]{2}{*}{$\begin{array}{l}\text { No of } \\
\text { person- } \\
\text { years }\end{array}$} & \multirow[b]{2}{*}{$\begin{array}{l}\text { No of } \\
\text { CRCs }\end{array}$} & \multirow[b]{2}{*}{$\begin{array}{l}\text { Incidence rate per } \\
100000 \text { person- } \\
\text { years }(95 \% \mathrm{Cl})\end{array}$} & \multicolumn{2}{|c|}{ At 10 years } & \multirow[b]{2}{*}{$\mathrm{P}$ value } & \multicolumn{2}{|c|}{ Standardisation } \\
\hline & & & & & & $\begin{array}{l}\text { No of } \\
\text { CRCs }\end{array}$ & $\begin{array}{l}\text { Cumulative } \\
\text { incidence }(95 \% \mathrm{Cl})^{*}\end{array}$ & & $\begin{array}{l}\text { No of } \\
\text { expected } \\
\text { CRCs } \ddagger\end{array}$ & $\operatorname{SIR}(95 \% \mathrm{CI})$ \\
\hline Unknown & 452 & 6 & 4115 & 9 & $219(114$ to 420$)$ & 8 & $2.7 \%(1.3$ to 5.4$)$ & & 9 & 1.03 (0.47 to 1.95$)$ \\
\hline Adenoma dysplasia** & & & & & & & & 0.71 & & \\
\hline Low-grade & 6912 & 90 & 55214 & 63 & 114 (89 to 146$)$ & 49 & $1.1 \%(0.8$ to 1.5$)$ & & 116 & 0.55 (0.42 to 0.70$)$ \\
\hline High-grade & 462 & 6 & 4059 & 3 & 74 (24 to 229$)$ & 3 & $0.9 \%(0.3$ to 2.9$)$ & & 9 & 0.32 (0.07 to 0.92$)$ \\
\hline Unknown & 267 & 3 & 2772 & 4 & 144 (54 to 384$)$ & 3 & $1.6 \%(0.5$ to 4.9$)$ & & 6 & 0.70 (0.19 to 1.78$)$ \\
\hline Proximal polypst† & & & & & & & & 0.23 & & \\
\hline No & 4649 & 61 & 38524 & 39 & 101 (74 to 139) & 31 & $1.1 \%(0.7$ to 1.5$)$ & & 78 & 0.50 (0.36 to 0.68$)$ \\
\hline Yes & 2992 & 39 & 23521 & 31 & 132 (93 to 187 ) & 24 & $1.2 \%(0.8$ to 1.9$)$ & & 53 & 0.59 (0.40 to 0.83$)$ \\
\hline
\end{tabular}

Low-risk patients were those without any of the following: $\geq 2$ PMPs, of which $\geq 1$ was advanced, $\geq 5$ PMPs or $\geq 1$ large ( $\geq 20 \mathrm{~mm})$ non-pedunculated PMP.

${ }^{*}$ Cumulative CRC incidence was estimated using the Kaplan-Meier method.

tP values were calculated with the log-rank test to compare cumulative CRC incidence among each category of the specified variable.

‡Numbers of expected CRCs were calculated by multiplying the 5-year age-group and sex-specific observed person-years by the corresponding CRC incidence rates in the general population of England in 2007.

\$PMP size was defined according to the largest PMP seen at baseline. Patients with PMPs of unknown size are not included in the table; in the analyses without surveillance, there were 27 such patients, of whom one was diagnosed with CRC; and in the analyses with one or more surveillance visits, there were 17 such patients with no CRC cases.

ๆAdenoma histology was defined according to the greatest degree of villousness seen at baseline.

**Adenoma dysplasia was defined according to the highest grade of dysplasia seen at baseline.

††Proximal polyps were defined as those proximal to the descending colon.

CRC, colorectal cancer; PMP, premalignant polyp; SIR, standardised incidence ratio.

$\geq 2$ PMPs, of which $\geq 1$ was advanced at baseline ( $29 \%$ of our cohort). This is important because in a resource-constrained setting, and given the serious, although rare, complications of colonoscopy due to its invasive nature, ${ }^{23}{ }^{24}$ surveillance should be directed towards patients at higher CRC risk than the general population after polypectomy. ${ }^{6}$

Applying the risk classification criteria in the 2020 UK guidelines, ${ }^{6} 29 \%$ of patients were classified as high risk, the same proportion as that identified as being at increased risk in our analyses of SIRs by baseline characteristics. Among these patients, CRC incidence without surveillance was 1.3 times higher than in the general population. Incidence was elevated to a larger extent in women than men, although the CIs of the SIRs overlapped. The elevated risk among these high-risk patients appeared to be largely driven by the presence of PMPs $\geq 20 \mathrm{~mm}$, adenomas with high-grade dysplasia, and proximal polyps, which warrant close attention from endoscopists. The excess risk was eliminated after first surveillance, indicating that the guideline recommendation for a one-off surveillance colonoscopy is appropriate.

The increased CRC risk associated with PMPs $\geq 20 \mathrm{~mm}$, adenomas with high-grade dysplasia, and proximal polyps might partly be the result of incomplete excision because the risk of incomplete excision is greater for advanced, large or proximal polyps. ${ }^{25}{ }^{26}$ Unfortunately, histological completeness of excision was not consistently recorded in our data and so we were unable to explore this hypothesis.

Among low-risk patients, CRC incidence without surveillance was lower than in the general population. Therefore, it is appropriate that this group are recommended to participate in their national CRC screening programme when invited rather than undergo surveillance, thereby minimising exposure of low-risk patients to unnecessary invasive surveillance procedures and alleviating pressures on endoscopy services. In the UK, screening involves the stoolbased faecal immunochemical test, currently offered biennially to people aged 60-74 years (50-74 years in Scotland). ${ }^{27} 28$ In this way, the new guidelines are expected to reduce surveillance colonoscopy workload by up to $80 \%$, compared with practice under the 2002 UK guidelines, ${ }^{2}$ although they will still ensure that high-risk patients are captured and receive surveillance. ${ }^{6}$
The 2020 UK guidelines are an improvement on the 2002 guidelines because they incorporate additional data on long-term postpolypectomy CRC outcomes. ${ }^{26}$ This is also true for the EU and US surveillance guidelines which were updated in $2020 .{ }^{78}$ However, there is still a lack of high-quality studies with CRC incidence or mortality as endpoints. Apart from the present study and our two previous analyses using this cohort, ${ }^{9}{ }^{10} 18$ only one other has compared post-polypectomy CRC incidence with that in the general population, in the absence and presence of surveillance. ${ }^{29}$ Cottet $e t$ al reported that, compared with the general population, CRC incidence was four times higher among patients with baseline adenomas $\geq 10 \mathrm{~mm}$, with villous features, or high-grade dysplasia without surveillance, but similar with $\geq 1$ surveillance visits. In contrast, CRC incidence among patients with tubular adenomas $<10 \mathrm{~mm}$ was comparable to that in the general population regardless of exposure to surveillance. However, this study had a small sample size $(\mathrm{n}=5779)$ and baseline colonoscopies were performed from 1990 to 1999 , predating colonoscopy quality improvements. ${ }^{29}$

A further three studies examining post-polypectomy CRC incidence were published in 2020. ${ }^{15-17}$ The findings from two of these indicate that, compared with patients with normal colonoscopy findings ('no adenomas' or 'no polyps'), patients with baseline adenomas $\geq 10 \mathrm{~mm}$, with villous features, or high-grade dysplasia, or serrated polyps $\geq 10 \mathrm{~mm}$ are at increased CRC risk, whereas patients with tubular adenomas or serrated polyps $<10 \mathrm{~mm}$ are not. ${ }^{15}{ }^{17} \mathrm{In}$ the third study, compared with the general population, CRC incidence was two times higher among patients with baseline adenomas $\geq 20 \mathrm{~mm}$; similar among those with adenomas with high-grade dysplasia; and two-thirds lower among those with adenomas $<20 \mathrm{~mm}$ with lowgrade dysplasia. ${ }^{16}$ These studies did not estimate CRC incidence without surveillance, which is a major limitation because surveillance differed in intensity and likely differentially affected CRC outcomes between the compared groups.

Serrated polyps have increasingly been recognised as important CRC precursors over the last two decades, ${ }^{30}$ but their natural history remains unclear because they have been examined in few long-term studies. Until recently, there was a lack of consensus regarding the nomenclature and histological classification of serrated polyps. ${ }^{30}$ 
Table 5 Cumulative incidence of colorectal cancer and age-sex-standardised incidence ratios in high-risk patients $(n=6239)$

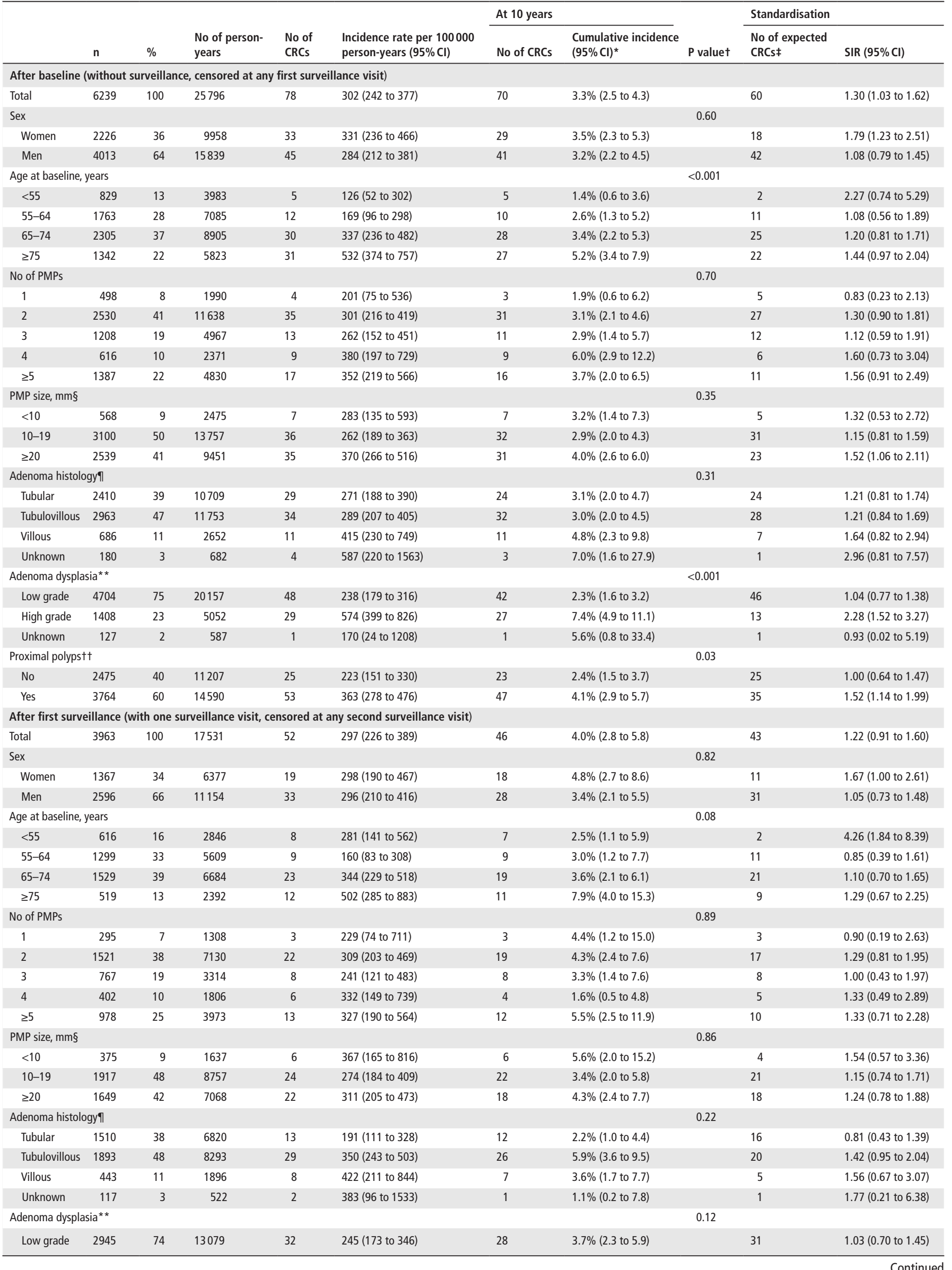


Table 5 Continued

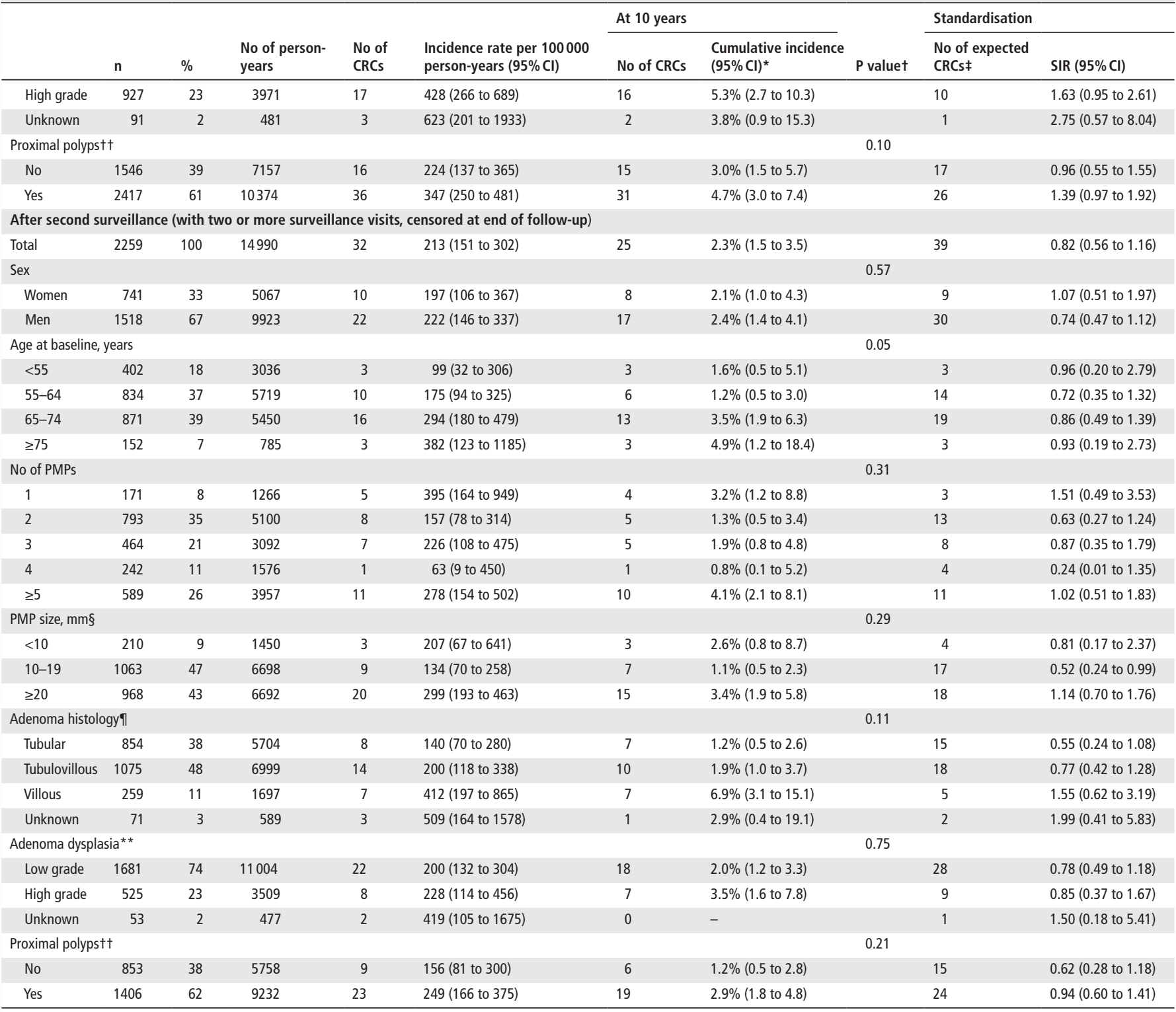

High-risk patients were those with $\geq 2$ PMPs, of which $\geq 1$ was advanced, $\geq 5$ PMPs or $\geq 1$ large ( $\geq 20 \mathrm{~mm}$ ) non-pedunculated PMP.

*Cumulative CRC incidence was estimated using the Kaplan-Meier method.

tP values were calculated with the log-rank test to compare cumulative CRC incidence among each category of the specified variable.

¥Numbers of expected CRCs were calculated by multiplying the 5-year age-group and sex-specific observed person-years by the corresponding CRC incidence rates in the general population of England in 2007.

§PMP size was defined according to the largest PMP seen at baseline. Patients with PMPs of unknown size are not included in the table; in the analyses without surveillance, there were 32 such patients with no CRC

cases; in the analyses with one surveillance visit, there were 22 such patients with no CRC cases; and in the analyses with two or more surveillance visits, there were 18 such patients with no CRC cases.

१Adenoma histology was defined according to the greatest degree of villousness seen at baseline.

**Adenoma dysplasia was defined according to the highest grade of dysplasia seen at baseline.

††Proximal polyps were defined as those proximal to the descending colon.

CRC, colorectal cancer; PMP, premalignant polyp; SIR, standardised incidence ratio.

Therefore, these lesions were likely under-recorded and misclassified in our dataset and so our serrated polyp data should be interpreted with caution. Moreover, all patients included as having serrated polyps in our dataset also had an adenoma at baseline, which might not be representative of a real-life population of patients with serrated polyps.

The observational design of our study means we cannot infer causality from the associations between baseline characteristics and CRC incidence. Moreover, this design is not necessarily ideally suited for determining optimal surveillance intervals. Randomised controlled trials comparing different surveillance intervals with CRC incidence as the endpoint, such as the FORTE (Five OR TEn year colonoscopy for 1-2 non-advanced adenomas) and EPoS (European Polyp Surveillance) trials, ${ }^{31} 32$ will provide additional data to inform whether the surveillance intervals recommended in the 2020 UK, EU and US guidelines are appropriate.

Another limitation is that as most examinations in our data occurred during the era of the 2002 UK guidelines, ${ }^{2}$ surveillance regimens advised for our cohort differed from current recommendations. Adherence to the guidelines was not complete, ${ }^{18}$ and the amount and frequency of surveillance varied across patients. To mitigate the effects of any associated bias, we controlled for number of surveillance visits in our analyses. We had incomplete information on why patients were attending follow-up examinations; therefore, some 'surveillance' examinations might have been for symptomatic purposes. Furthermore, we had no information on reasons for non-attendance at surveillance. It is possible that some patients underwent surveillance at hospitals other than those 
from which we obtained data. Baseline data were more frequently missing for patients attending surveillance compared with nonattenders which might have introduced bias. Our use of routinely collected data means that misclassification is likely present in the dataset. Finally, we might be overestimating CRC incidence in the general population as compared with our cohort; while we excluded patients who had CRC at or before baseline colonoscopy from our cohort, this exclusion did not apply to the general population.

Strengths include the large size, nationwide design and detailed information on baseline patient, procedural, and polyp characteristics and surveillance examinations. There were few missing data and losses to follow-up were minimal. We restricted our dataset to patients with a high-quality baseline colonoscopy and so the findings are applicable to contemporary colonoscopy practice. We used the definitive endpoint of CRC incidence and accounted for the effects of surveillance on our incidence estimates; this enabled us to elucidate the effects of individual baseline characteristics on long-term post-polypectomy CRC incidence.

\section{CONCLUSION}

Our findings demonstrate that the 2020 UK guidelines accurately identify patients at high risk of CRC after polypectomy, and that the recommendation for a one-off surveillance colonoscopy seems appropriate for these patients and would help eliminate their excess risk. Moreover, these guidelines will ensure that low-risk patients, who we showed are very unlikely to develop CRC after polypectomy, are not exposed to unnecessary surveillance colonoscopies and are appropriately managed by population-based non-invasive CRC screening instead.

Twitter CSPRG @CSPRG_Imperial

Acknowledgements We would like to acknowledge Professor Wendy Atkin who was the original Chief Investigator of the study, who sadly passed away in 2018. We would also like to thank the people named below for their involvement in the study. A special thank you to all the patients who contributed data to the study.

Collaborators Trial steering committee: Dr Andrew M Veitch (Chair), Professor Allan Hackshaw, Professor Steve Morris, Professor Colin Rees, and Ms Helen Watson (patient representative). Cancer Screening and Prevention Research Group staff: Mrs Elizabeth Coles, Dr Paula Kirby and Dr Eilidh MacRae. Participating hospitals: We would like to thank the principal investigators, gastroenterologists, endoscopists, surgeons, nurses, pathologists, administrative staff and ICT staff at each of the hospitals named below. We would also like to thank everyone who helped us collect endoscopy and pathology data for the study. Royal Sussex County Hospital, Brighton. Cumberland Infirmary, Carlisle; Imperial College Healthcare Trust: Charing Cross Hospital/Hammersmith Hospital and St Mary's Hospital, London; Glasgow Royal Infirmary, Glasgow. Leicester General Hospital, Leicester; Royal Liverpool University Hospital, Liverpool; New Cross Hospital, Wolverhampton; University Hospital of North Tees, Stockton-on-Tees; Queen Elizabeth Hospital, Woolwich, London; Queen Mary's Hospital, Sidcup, Kent; Royal Shrewsbury Hospital, Shropshire.; St George's Hospital, Tooting, London; St Mark's Hospital, Harrow, London; Royal Surrey County Hospital, Surrey; Torbay District General Hospital, Devon; Yeovil District Hospital, Somerset.

Contributors $\mathrm{AJC}$ and $\mathrm{KW}$ were responsible for study design and obtaining funding. IS, KP, and BP were responsible for data acquisition, cleaning, and coding AJC, KW, and SWD were responsible for oversight of data analysis. KW performed the statistical analyses. AJC, KW, and ECR interpreted the data. ECR wrote the first draft of the manuscript. AMV, BPS, and MDR critically evaluated the findings and provided clinical insight. All authors critically appraised the final manuscript and gave final approval of the version to be published.

Funding This is a summary of independent research funded by the National Institute for Health Research (NIHR) Health Technology Assessment (HTA) programme (reference NIHR-HTA 15/80/13) and a Cancer Research UK Population Research Committee Programme Award (reference C53889/A25004).

Disclaimer The funders had no role in the study design, data collection, analysis, or interpretation, manuscript writing, or decision to submit for publication. The views expressed are those of the authors and not necessarily those of the NHS, the NIHR, the Department of Health, or Cancer Research UK. Infrastructure support for this work was provided by the NIHR Imperial Biomedical Research Centre.
Competing interests $A J C$, as Chief Investigator, was the recipient of all the funding. MDR reports personal fees from Swiss SCWeb AG, Pentax, and Norgine, and a grant from Olympus, outside the submitted work.

\section{Patient consent for publication Not required.}

Ethics approval The Royal Free Research Ethics Committee (REC) granted approval for our original study of patients classified as 'intermediate-risk' based on baseline adenoma characteristics, according to the 2002 UK surveillance guidelines (REC reference 06/Q0501/45). Further ethics approval was granted by the London - Hampstead REC (formerly the Royal Free REC) and the Health Research Authority (HRA) for the substantial amendments that extended the scope of the protocol to examine all patients with adenomas at baseline and to apply the new risk classification criteria in the 2020 UK surveillance guidelines (REC reference 06/Q0501/45, IRAS ID 55943). Approval for the processing of patient identifiable information without consent was originally granted by the Patient Information Advisory Group (PIAG) under Section 60 of the Health and Social Care Act 2001 (re-enacted by Section 251 of the NHS Act 2006) and subsequent amendments / annual reviews were approved by the HRA-Confidentiality Advisory Group (reference PIAG 1-05[e]/2006)

Provenance and peer review Not commissioned; externally peer reviewed.

Data availability statement Data are available upon reasonable request. We may be able to share de-identified participant data with researchers following publication of this manuscript. Requests for data should be directed to the corresponding author. Data sharing will need to be approved by third party data providers.

Supplemental material This content has been supplied by the author(s). It has not been vetted by BMJ Publishing Group Limited (BMJ) and may not have been peer-reviewed. Any opinions or recommendations discussed are solely those of the author(s) and are not endorsed by BMJ. BMJ disclaims all liability and responsibility arising from any reliance placed on the content. Where the content includes any translated material, BMJ does not warrant the accuracy and reliability of the translations (including but not limited to local regulations, clinical guidelines, terminology, drug names and drug dosages), and is not responsible for any error and/or omissions arising from translation and adaptation or otherwise.

Open access This is an open access article distributed in accordance with the Creative Commons Attribution 4.0 Unported (CC BY 4.0) license, which permits others to copy, redistribute, remix, transform and build upon this work for any purpose, provided the original work is properly cited, a link to the licence is given, and indication of whether changes were made. See: https://creativecommons.org/ licenses/by/4.0/.

\section{ORCID iDs}

Amanda J Cross http://orcid.org/0000-0002-0893-2377

Matthew D Rutter http://orcid.org/0000-0001-9507-0295

\section{REFERENCES}

1 Zauber AG, Winawer SJ, O'Brien MJ, et al. Colonoscopic polypectomy and long-term prevention of colorectal-cancer deaths. N Engl J Med 2012;366:687-96.

2 Atkin WS, Saunders BP, et al, British Society for Gastroenterology. Surveillance guidelines after removal of colorectal adenomatous polyps. Gut 2002;51 Suppl 5:V6-9.

3 Atkin WS, Valori R, Kuipers EJ, et al. European guidelines for quality assurance in colorectal cancer screening and diagnosis. First Edition--Colonoscopic surveillance following adenoma removal. Endoscopy 2012;44 Suppl 3:SE151-63.

4 Hassan C, Quintero E, Dumonceau J-M, et al. Post-polypectomy colonoscopy surveillance: European Society of gastrointestinal endoscopy (ESGE) guideline. Endoscopy 2013;45:842-64.

5 Lieberman DA, Rex DK, Winawer SJ, et al. Guidelines for colonoscopy surveillance after screening and polypectomy: a consensus update by the US Multi-Society Task force on colorectal cancer. Gastroenterology 2012;143:844-57.

6 Rutter MD, East J, Rees CJ, et al. British Society of Gastroenterology/Association of Coloproctology of great britain and Ireland/Public health England post-polypectomy and post-colorectal cancer resection surveillance guidelines. Gut 2020;69:201-23.

7 Gupta S, Lieberman D, Anderson JC, et al. Recommendations for Follow-Up After Colonoscopy and Polypectomy: A Consensus Update by the US Multi-Society Task Force on Colorectal Cancer. Gastrointest Endosc 2020;91:e465:463-85.

8 Hassan C, Antonelli G, Dumonceau J-M, et al. Post-polypectomy colonoscopy surveillance: European Society of Gastrointestinal Endoscopy (ESGE) Guideline Update 2020. Endoscopy 2020;52:687-700.

9 Atkin W, Wooldrage K, Brenner A, et al. Adenoma surveillance and colorectal cancer incidence: a retrospective, multicentre, cohort study. Lancet Oncol 2017;18:823-34.

10 Atkin W, Brenner A, Martin J, et al. The clinical effectiveness of different surveillance strategies to prevent colorectal cancer in people with intermediate-grade colorectal adenomas: a retrospective cohort analysis, and psychological and economic evaluations. Health Technol Assess 2017;21:1-536. 
11 Click B, Pinsky PF, Hickey T, et al. Association of colonoscopy adenoma findings with long-term colorectal cancer incidence. JAMA 2018;319:2021-31.

12 Løberg M, Kalager M, Holme Øyvind, et al. Long-Term colorectal-cancer mortality after adenoma removal. N Engl J Med Overseas Ed 2014;371:799-807.

13 Nishihara R, Wu K, Lochhead P, et al. Long-Term colorectal-cancer incidence and mortality after lower endoscopy. N Eng/ J Med 2013;369:1095-105.

14 Lee JK, Jensen CD, Levin TR, et al. Long-Term risk of colorectal cancer and related deaths after a colonoscopy with normal findings. JAMA Intern Med 2019;179:153-60.

15 Lee JK, Jensen CD, Levin TR, et al. Long-Term risk of colorectal cancer and related death after adenoma removal in a large, community-based population. Gastroenterology 2020;158:e885:884-94.

16 Wieszczy P, Kaminski MF, Franczyk R, et al. Colorectal cancer incidence and mortality after removal of adenomas during screening Colonoscopies. Gastroenterology 2020;158:e875:875-83.

17 He X, Hang D, Wu K, et al. Long-Term risk of colorectal cancer after removal of conventional adenomas and serrated polyps. Gastroenterology 2020;158:e854:852-61.

18 Cross AJ, Robbins EC, Pack K, et al. Long-Term colorectal cancer incidence after adenoma removal and the effects of surveillance on incidence: a multicentre, retrospective, cohort study. Gut 2020;69:1645-58.

19 Hossain E, Alkandari A, Bhandari P. Future of endoscopy: brief review of current and future endoscopic resection techniques for colorectal lesions. Dig Endosc 2020:32:503-11.

20 Office for National Statistics. Cancer registration statistics, England, 2007. Available: http://www.ons.gov.uk/peoplepopulationandcommunity/healthandsocialcare/conditio nsanddiseases/datasets/cancerregistrationstatisticscancerregistrationstatisticsengland [Accessed Jun 2020].

21 StataCorp LP. Stata statistical software: release 13. Texas, USA, 2013.
22 Cross AJ. Retrospective cohort study to examine the long-term colorectal cancer risk and surveillance requirements following diagnosis of adenomas (The All Adenomas study). National Institute for Health Research (NIHR) Health Technology Assessment (HTA) programme 15/80/13, 2017. Available: https://www.journalslibrary.nihr.ac.uk/ programmes/hta/158013/\#/ [Accessed June 2020].

23 Ko CW, Riffle S, Michaels L, et al. Serious complications within 30 days of screening and surveillance colonoscopy are uncommon. Clin Gastroenterol Hepatol 2010;8:166-73.

24 Whitlock EP, Lin JS, Liles E, et al. Screening for colorectal cancer: a targeted, updated systematic review for the U.S. preventive services Task force. Ann Intern Med 2008; 149:638-58

25 Lee SP, Sung IK, Kim JH, et al. Risk factors for incomplete polyp resection during colonoscopic polypectomy. Gut Liver 2015;9:66-72.

26 Herszényi L. The "Difficult" Colorectal Polyps and Adenomas: Practical Aspects. Dig Dis 2019;37:394-9.

27 Public Health England (PHE) screening. Bowel cancer screening: programme overview 2015. Available: https://www.gov.uk/guidance/bowel-cancer-screening-programmeoverview [Accessed Jun 2020].

28 Public Health Scotland. Bowel screening, 2020. Available: http://www.healthscotland. scot/health-topics/screening/bowel-screening [Accessed Jun 2020].

29 Cottet V, Jooste V, Fournel I, et al. Long-Term risk of colorectal cancer after adenoma removal: a population-based cohort study. Gut 2012;61:1180-6.

30 East JE, Atkin WS, Bateman AC, et al. British Society of gastroenterology position statement on serrated polyps in the colon and rectum. Gut 2017:66:1181-96.

31 Jover R, Bretthauer M. Clinicaltrials.Gov. identifier NCT02319928. European polyp surveillance trial (EPOS). Bethesda, Maryland: U.S. National library of medicine, 2014 Available: https://clinicaltrials.gov/ct2/show/NCT02319928 [Accessed Jun 2020].

32 Weinberg DS, Schoen RE. Preneoplastic Colorectal Polyps: "I Found Them and Removed Them-Now What?". Ann Intern Med 2019;171:667. 